\title{
DEVELOPMENT OF CROP SPECTRA FOR VARIATIONS IN NITROGEN AND WATER APPLIED IN UNREGULATED FARMER'S FIELD PLOTS BASED ON SPECTRAL SIMILARITY WITH SPECTRA COLLECTED FROM REGULATED TEST FIELD PLOTS
}

\author{
Hasmukh Chauhan* \\ Birla Vishvakarma Mahavidyalaya, Vallabh Vidya Nagar, Gujarat, India - hjchauhan@bvmengineering.ac.in
}

Commission V, SS: Natural Resources Management

KEY WORDS: regulated field plots, spectral similarity and spectral information divergence

\begin{abstract}
:
To develop crop spectra for variation in application of nitrogen (as fertilizer) and water at farmer's field plots is very difficult as there are large variations in nitrogen and water applied also time of applications were different. During field visit it was found that various crops growth was not uniform in the study area even though local conditions (seed quality, soil and weather) were same this is possible due to variation in application of nitrogen and water. Development of crop spectra for nitrogen and water variations for unregulated farmer's field plots based on spectral similarity analysis with regulated test field plots (where required amount of nitrogen and water applied at appropriate time) provides a fresh opportunity to develop and evaluate the crop spectra for nitrogen and water variations for real time applications. Spectral Information Divergence (SID) based spectral similarity analysis was carried out among spectra collected from unregulated farmer's field plots and regulated test field plots for chickpea, sorghum and wheat crops. An average SID values equivalent to coefficient of correlation computed for four groups of nitrogen and water variations for chickpea, sorghum and wheat were $0.998,0.996$ and 0.994 respectively.
\end{abstract}

\section{INTRODUCTION}

It is very essential to monitor the actual growth of the crops. The major two factors which govern the growth of the crops were timely and appropriate application of nitrogen (as fertilizer) and water. To monitor or collect data for nitrogen and water applied from actual field is quite cumbersome or very difficult. Spectral similarity measures were effectively used to distinguish among vegetation and background soil (Chang, 2000) and (Du et al., 2004) to distinguish among mineral spectra (Van Der Meer, 2004) discriminating crop varieties (Kong et al., 2010) and developing precise field crop spectra based on collected field spectra (Chauhan B. Krishna, 2014). Filella and Penuelas (1994) studied the effect of optimum and deficit nitrogen and water applied to various crop and carried out shape analysis of spectra due to variation in nitrogen and water applied. Major four groups: HNHW (High Nitrogen High Water), HNLW (High Nitrogen Low Water), LNHW (Low Nitrogen High Water) and LNLW (Low Nitrogen Low Water) was formed to study the problem of deficiency in Nitrogen and water applied.

Field spectral library for the study area for chickpea and wheat built after processing the collected spectra. Field spectra also collected from the controlled field condition of variation in nitrogen and water applied at site of Indian Agriculture Research Institute (IARI), New Delhi for both the crops. Hence a try has been made to check spectral similarity of the spectra collected in the controlled field conditions with the spectra collected from uncontrolled (study area) field conditions. A good match among the spectra leads to use of matched spectra for the classification of the remote sensing image for condition of the crop. It makes monitoring of the crops a manageable task as data collection for variety of crops for nitrogen and water applied for variety of the crops is quite cumbersome and time consuming.

To carry out the spectral similarity between field spectra of controlled site condition (at IARI) to uncontrolled site conditions (study area) Spectral Information Measure (SIM) based Spectral Information Divergence (SID) is used as similarity measure. SID computes the spectral similarity between two pixels vectors by the discrepancy between their corresponding spectral signature-derived probability distribution.

\section{STUDY AREA AND FIELD DATA COLLECTED}

Study area covers the regions with central coordinates $20^{\circ} \mathrm{N}$ latitude and $76.5^{\circ} \mathrm{E}$ longitudes are Lonar, Mehekar in Buldhana District of Maharashtra, India. Study area having climate of tropical semi arid with alluvial soil types. The area is productive having irrigated crops in Rabi season (OctoberFebruary). The major crops during Rabi season are chickpea, sorghum and wheat. The minor crops are seasonal vegetable and fruits. During field visit field spectra are collected from the plots in which time gap in sowing of the crops was not more than one week. Also average age of the crops was 60 days. As

\footnotetext{
* Corresponding author
} 
local weather conditions are same; timely and appropriate (quantity) application of nitrogen (as fertilizer) and water affect the growth of the crops. Plots are selected in such way that visually infections in the crops were not observed. Hence if crops are stressed it is mostly due to inappropriate application of nitrogen (as fertilizer) and water.

Field observations were carried out for major three crops chickpea, sorghum and wheat. The field observations include ground based hyperspectral reflectance using GER 1500 spectroradiometer with GPS locations covering all major crop types. The field observations were taken over 106 sites. The spectroradiometer has a range of 512 channels with a range of 325 to $1075 \mathrm{~nm}$. Gathering spectra at a given location involves optimizing the integration time providing fore-optic information, recording dark current and collecting white reference reflectance. The target reflectance is the ratio of energy reflected off the target (crop) to energy incident on the target (measured using $\mathrm{BaSO} 4$ white reference). The reflectance measurements were made from one meter above the crop canopy with the sensor facing the crop and oriented normal to the plant. The readings were taken on cloud free days at around solar before noon local time. While taking the observations, explicit care was taken not to cast shadows over the area being scanned by the instrument. Spectral library for specific crop built form the collected spectra (Rao et. al., 2007) and (Gomez, 2001). Precision of the spectra checked and outlier were rejected to build precise spectral library (Chauhan and B. Krishna, 2014).

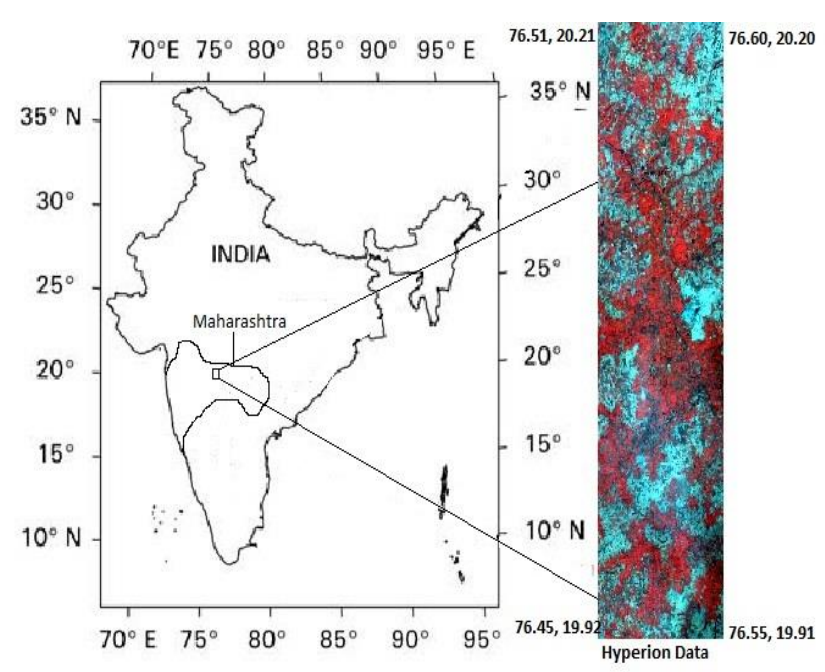

Figure 1: Location of Study Area and Hyperspectral Data

Field data of the chickpea and wheat crops for controlled field conditions are also collected at the test sites at the average age of 60 days of Indian Agriculture Research Institute (IARI), New Delhi. These crops in the test bed are regulated for nitrogen and water. Optimum (100\%) and $50 \%$ of optimum nitrogen and water were applied to crops. Optimum was termed as High and $50 \%$ of optimum was termed as Low and four groups of spectra HNHW, HNLW, LNHW and LNLW were formed.

\section{METHODOLOGY}

Spectral information based spectra information divergence is used as spectral similarity measure.

\subsection{Spectral Information Measure (SIM)}

SIM (Kullback, 1997) is an information theoretic measure that models the spectral band-to-band variability as uncertainty resulting from randomness. It considers each pixel vector as a random variable with the probability distribution obtained by normalizing its spectral histogram to unity. With this interpretation, SIM can measure the spectral variability of a single hyperspectral pixel vector resulting from band-to-band correlation. So, SIM can be considered as a single pixel vector based stochastic measure. It is particularly useful for hyperspectral image analysis. This is because the spectral information provided by each hyperspectral image pixel vector can improve material detection, discrimination, classification and identification.

For a given hyperspectral pixel vector $\mathbf{x}=\left(x_{1}, \mathrm{x}_{2}, \ldots, x_{\mathrm{L}}\right)^{\mathrm{T}}, \mathbf{x}$ can be modeled as a random variable by defining an appropriate probability measure. In order to define legitimate probability measure $P$ for $\mathbf{x}$, we first assume that all components $s l$ 's associated with $\mathbf{x}$ are nonnegative. This is generally a valid assumption due to the nature of radiance or reflectance. With this assumption, we can normalize $x_{l}$ 's to the range of $[0,1]$ as follows,

$$
P_{k}=s_{i k} \sum_{l=1}^{L} S i l
$$

Using equation (1) a probability measure $P$ for $\mathbf{x}$ can be defined as,

$$
\mathrm{P}\left(\left\{\boldsymbol{\omega}_{l}\right\}\right)=p_{l}
$$

The probability vector $p=\left(p_{1}, p_{2}, \ldots \ldots \ldots . . p_{L}\right)^{T}$ is the desired probability distribution of pixel vector $\mathbf{x}$. By means of this probability interpretation, any pixel vector $\mathrm{x}=\left(x_{1} \ldots \ldots \ldots, x_{\mathrm{L}}\right)^{\mathrm{T}}$ can be viewed as a single information source with its statistics governed by $p=\left(p_{1}, p_{2}, \ldots \ldots \ldots . . . p_{L}\right)^{T}$ defined by (1) and (2). As a result, these statistics can be used to describe the spectral variability of a pixel vector. Since a hyperspectral image pixel vector $\mathbf{x}$ can be considered as an information source described by (1) and (2), from information theory self-information provided by band $l$ can be defined by

$$
I_{l}(x)=-\log \left(p_{l}\right)
$$

\subsection{Spectral Information Divergence (SID)}

A new criterion to measure spectral similarity, called SID (Chang, 2000) and (Chang, 2003) is presented in this section. It originates from the concept of divergence in information theory and measures the discrepancy of probabilistic behaviours between the spectral signatures of two pixel vectors. In other 
words, the spectral similarity between two pixels vectors is measured by SID based on the discrepancy between their corresponding spectral signature-derived probability distribution. SID is one such measure which measures the distance between the probability distributions produced by the spectral signatures of two pixel vectors.

Two probability vectors $\mathrm{p}=\left(p_{1}, p_{2}, \ldots \ldots \ldots . . . p_{L}\right)^{T}$ and $q=\left(q_{1}\right.$, $\left.q^{2}, \ldots \ldots \ldots \ldots q_{L}\right)^{T}$ for the spectral signatures of two pixel vectors $\mathrm{si}$ and $\mathrm{s}_{\mathrm{j}}$ where $p_{k}=s_{i k} / \sum_{l=1}^{L}$ sil and $q_{k}=s_{j k} / \sum_{l=1}^{L} s_{j l}$. So, the self-information provided by $\mathbf{r}_{\mathrm{j}}$ (pixel vector) for band $l$ is defined by (4) and given by

$\left(\mathrm{r}_{\mathrm{j}}\right) \quad=\quad-\quad \log$

4)

Using (3) and (4), $D_{l}\left(r_{i} \| r_{j}\right)$ can be defined which is the discrepancy in the self-information of band $l$ in $\mathbf{r}_{j}$ relative to the self-information of band $l$ in $\mathbf{r}_{\mathbf{i}}$ (Cover and Thomas, 1991) by,

$$
\begin{aligned}
& D_{l}\left(\mathrm{r}_{\mathrm{i}} \| \mathrm{r}_{\mathrm{j}}\right)=I_{l}\left(\mathrm{r}_{\mathrm{j}}\right)-I_{l}\left(\mathrm{r}_{\mathrm{i}}\right)=\left(-\log q_{l}\right)-\left(-\log p_{l}\right) \\
& =\log \left(p_{l} / q_{l}\right)
\end{aligned}
$$

Averaging $D_{l}\left(\mathrm{r}_{\mathrm{i}} \| \mathrm{r}_{\mathrm{j}}\right)$ in (5) overall bands $1 \leq l \leq L$ with respect to $r_{i}$ results in

$$
\begin{gathered}
D\left(\mathrm{r}_{i} \| \mathrm{r}_{\mathrm{j}}\right)=\sum_{l=1}^{L} \quad p_{l} D_{l}\left(\mathrm{r}_{\mathrm{i}} \| \mathrm{r}_{\mathrm{j}}\right)=\sum_{l=1}^{L} p_{l}\left(I_{l}\left(\mathrm{r}_{\mathrm{j}}\right)-I_{l}\left(\mathrm{r}_{\mathrm{i}}\right)\right) \\
=\sum_{l=1}^{L} p_{l} \log \left(p_{l} / q_{l}\right)
\end{gathered}
$$

Where $D\left(\mathrm{r}_{\mathrm{i}} \| \mathrm{r}_{\mathrm{j}}\right)$ is the average discrepancy in the selfinformation of $\mathbf{r}_{j}$ relative to the self-information of $\mathbf{r}_{i}$. In context of information theory $D\left(\mathrm{r}_{\mathrm{i}} \| \mathrm{r}_{\mathrm{j}}\right)$ in (6) is called the relative entropy of $\mathbf{r}_{j}$ with respect to $\mathbf{r}_{i}$ which is also known as KullbackLeibler information measure, directed divergence or cross entropy [9]. Similarly, average discrepancy in the selfinformation of $\mathbf{r}_{j}$ relative to the self-information of $\mathbf{r}_{i}$ by

$$
\begin{gathered}
D\left(\mathrm{r}_{j} \| \mathrm{r}_{\mathrm{i}}\right)=\sum_{l=1}^{L} \quad q_{l} D_{l}\left(\mathrm{r}_{\mathrm{j}} \| \mathrm{r}_{\mathrm{i}}\right)=\sum_{l=1}^{L} q_{l}\left(I_{l}\left(\mathrm{r}_{\mathrm{i}}\right)-I_{\mathrm{l}}\left(\mathrm{r}_{\mathrm{j}}\right)\right) \\
=\sum_{l=1}^{L} \quad q_{l} \log \left(q_{l} / p_{l}\right)
\end{gathered}
$$

Summing (6) and (7) yields spectral information divergence (SID) defined by,

$$
\operatorname{SID}\left(\mathbf{r}_{\mathrm{i}}, \mathbf{r}_{\mathbf{j}}\right)=D\left(\mathrm{r}_{i} \| \mathrm{r}_{\mathrm{j}}\right)+D\left(\mathrm{r}_{j} \| \mathrm{r}_{\mathrm{i}}\right)
$$

Equation (8) can be used to measure the spectral similarity between two pixel vectors $\mathbf{r}_{i}$ and $\mathbf{r}_{\mathrm{j}}$. It should be noted that while $\operatorname{SID}\left(\mathbf{r}_{i}, \mathbf{r}_{\mathbf{j}}\right)$ is symmetric, $D\left(\mathrm{r}_{i} \| \mathrm{r}_{\mathrm{j}}\right)$ is not. This is because $\operatorname{SID}\left(\mathbf{r}_{\mathrm{i}}, \mathbf{r}_{\mathrm{j}}\right)=\operatorname{SID}\left(\mathrm{r}_{j}, \mathrm{r}_{\mathrm{i}}\right)$ but $D\left(\mathrm{r}_{i} \| \mathrm{r}_{\mathrm{j}}\right) \neq D\left(\mathrm{r}_{j} \| \mathrm{r}_{\mathrm{i}}\right)$.

\section{RESULTS AND DISCUSSION}

Major four groups: HNHW (High Nitrogen High Water), HNLW (High Nitrogen Low Water), LNHW (Low Nitrogen High Water) and LNLW (Low Nitrogen Low Water) was formed to study the problem of deficiency in Nitrogen and water applied. Differences in vegetation vigor, resulting from variation in nitrogen and water applied, are especially evident when Near Infrared imagery or data are used. Stress is indicated by progressive decrease in Near-IR reflectance. Collected spectra for four conditions of crops i.e. HNHW, HNLW, LNHW and LNLW are as shown in figure 2.

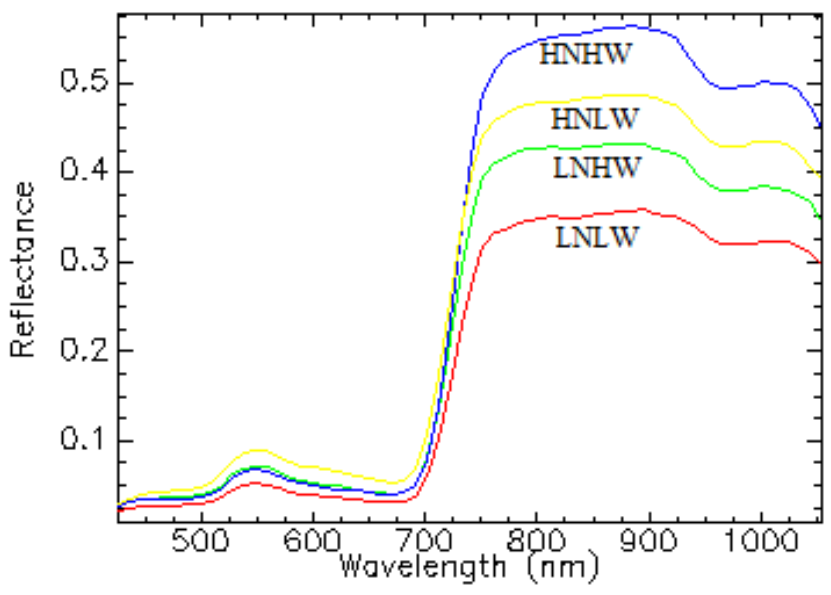

(a)

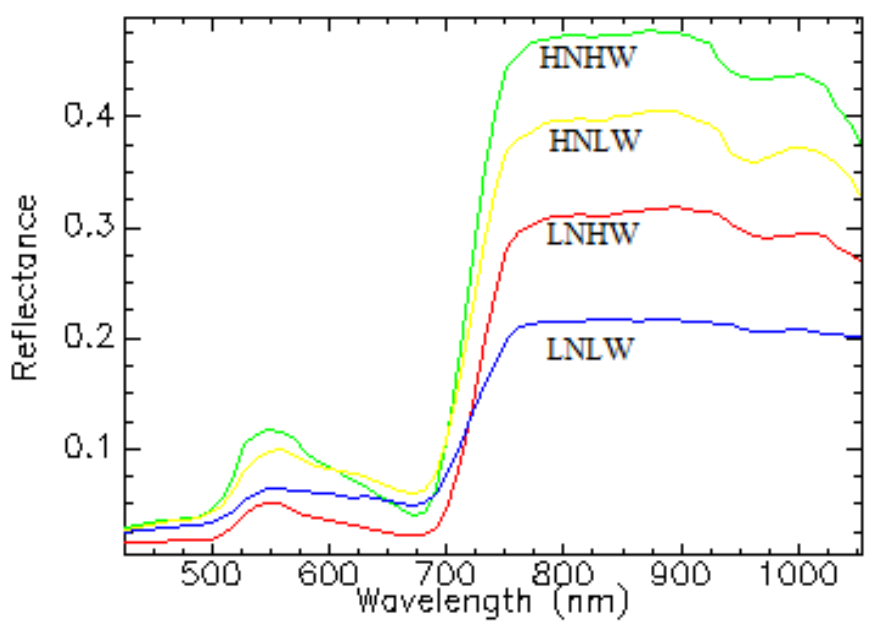

(b)

Figure 2: Crop Spectra , a) Chickpea, and b) Wheat for four condition HNHW (High Nitrogen High Water), HNLW (High Nitrogen Low Water), LNHW(Low Nitrogen High Water) and LNLW (Low Nitrogen Low Water) in controlled nitrogen (as fertilizer) and water applied conditions

Spectral similarity analysis using SID is carried out between the collected field spectra and spectra collected in controlled condition of nitrogen and water applied. Similarity values were computed among various spectra of controlled crop conditions as HNHW, HNLW, LNHW and LNLW and all collected field spectra of study area for a 
specific crop. Field spectra of the crops were assigned to a controlle crop spectrum of a specific condition where close match has been Gloseness observed. Separately for both crops this analysis was carried out. Measure Based on matching of coefficient of correlation and spectral similarify values, a spectra is assigned to specific health condition which produce very close match. Similarity results are tabulated in table 1 . Table: 1 shows very close match between coefficient of correlation and SID value equivalent to coefficient of correlation derived for crop Chickpea spectral library generated in controlled conditions and uncontrolled (study area ) conditions. Build spectral library for variation in nitrog $\mathrm{n}$ and water for uncontrolled (study area) conditions is as shown in figure 3. Hence spectral similarity based crop health analysis provides an effective and possible alternative to quantify field crop condition Wheat based on knowledge derived from controlled field conditions.

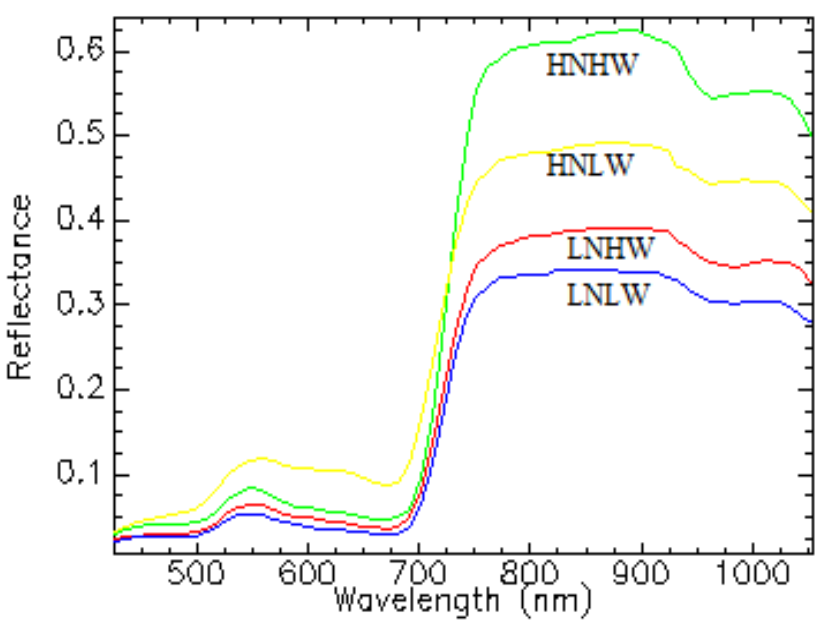

(a)

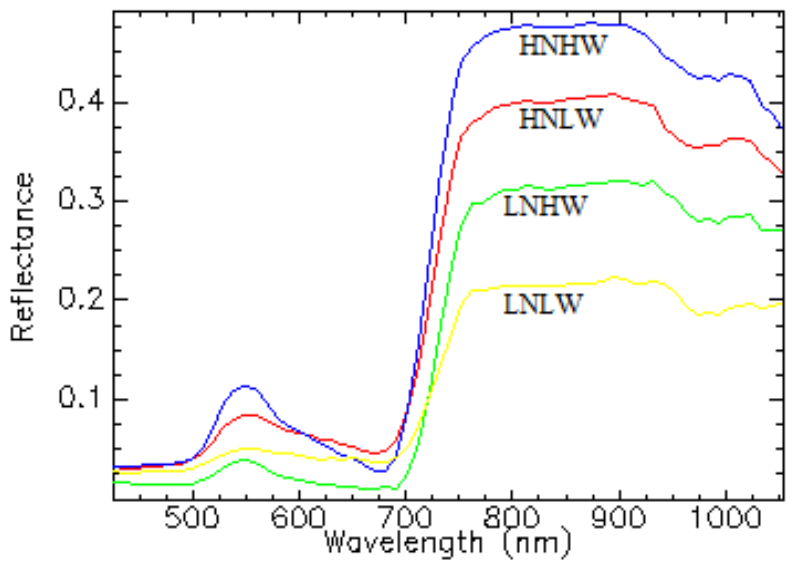

(b)

Figure 3: Field Crop Spectra of, a) Chickpea and b) Wheat for four condition HNHW (High Nitrogen High Water), HNLW (High Nitrogen Low Water), LNHW (Low Nitrogen High Water) and LNLW (Low Nitrogen Low Water) developed based on spectral similarity with controlled field conditions.

Table1: Coefficient of Correlation and SID spectral similarity value between crop spectra for controlled and uncontrolled (study area) field conditions for Nitrogen and Water variations

\begin{tabular}{|c|c|c|c|}
$\begin{array}{c}\text { Crop } \\
\text { Condition }\end{array}$ & $\begin{array}{c}\text { Coefficient } \\
\text { of } \\
\text { Correlation }\end{array}$ & $\begin{array}{c}\text { SID } \\
\text { Value } \\
\text { (Distance } \\
\text { Measure } \\
\text { Value) }\end{array}$ & $\begin{array}{c}\text { SID Value } \\
\text { Equivalent } \\
\text { to } \\
\text { Coefficient } \\
\text { of } \\
\text { Correlation }\end{array}$ \\
\hline HNHW & 0.9998 & 0.0003 & 0.9997 \\
\hline HNLW & 0.9978 & 0.0063 & 0.9937 \\
\hline LNHW & 0.9995 & 0.0003 & 0.9997 \\
\hline LNLW & 0.9992 & 0.0004 & 0.9996 \\
\hline HNHW & 0.9968 & 0.0025 & 0.9975 \\
\hline HNLW & 0.9974 & 0.0157 & 0.9843 \\
\hline LNHW & 0.9967 & 0.0042 & 0.9958 \\
\hline LNLW & 0.9978 & 0.0022 & 0.9978 \\
\hline
\end{tabular}

*SID Value equivalent to Coefficent of Correlation = 1- Distance Measure Value

\section{CONCLUSION}

It was quite difficult to develop crop spectra for nitrogen and water variations for actual field conditions as there is large variations in nitrogen (as fertilizer) and water applied. During field visit it was found that crop growth was not uniform in the study area even though local conditions were same. Development of crop spectra for nitrogen and water variations for uncontrolled (study area) field conditions based on spectral similarity analysis with controlled field conditions provides a fresh opportunity to develop and evaluate the crop spectra for nitrogen and water variations for real time applications.

\section{REFERENCES}

Chang, C.I., 2000. An information theoretic-based approach to spectral variability, similarity and discriminability for hyperspectral image analysis. IEEE Transaction on Information Theory, 46 (5), 1927-1932.

Chang, C.I., 2003. Hyperspectral Imaging: Techniques for Spectral Detection and Classification. Kluwer Academic / Plenum Publishers, New York.

Chauhan Hasmukh and B. Krishna Mohan. 2014. Effectiveness of spectral similarity measures to develop precise crop spectra for Hyperspectral data analysis, ISPRS Annals of Photogrammetry, Remote Sensing and Spatial Information Sciences, Volume II-8, 2014.DOI:10.5194/isprsannals-II-8-842014.

Cover, T and Thomas, J. 1991. Elements of Information Theory, New York: Wiley. ISBN 0-471-06259-6.

Du H., C.I. Chang, H. Ren, F.M. D'Amico, J. O. and Jensen J. 2004. New Hyperspectral Discrimination Measure for Spectral 
Characterization. Optical Engineering. Vol. 43, No. 8, 17771786.

Filella I., and Penuelas J. 1994. The red edge position and shape as indicators of plant chlorophyll content, biomass and hydric status, International Journal of Remote Sensing, vol: 15, no.7, pp. 1459-1470.

Gomez, R.B. 2001. Spectral Library Issues in Hyperspectral Imaging Applications. Paper presented at the $5^{\text {th }}$ Joint Conference on Standoff detection for Chemical and Biological Defense, Williamsburg, Virginia, 24-28, September, 2001.

Kong Xiangbing, Shu Ning, Huang Wenyu and Fu Jing, 2010. The Research on Effectiveness of Spectral Similarity Measures for Hyperspectral Image. Presented in 3rd International Congress on Image and Signal Processing (CISP2010), 978-14244-6516-2010, IEEE.

Kullback, S. 1997. Information Theory and Statistics, Dover Gloucester, MA.

Rao N.R., Garg P.K. and Ghosh, S.K. 2007. Development of an agricultural crops spectral library and classification of crops at cultivar level using hyperspectral data. Precision Agriculture, 8: 173-185, DOI: 10.1007/s11119-007-9037-x.

Van der Meer F. 2005. The effectiveness of spectral similarity measures for the analysis of hyperspectral imagery. International Journal of Applied Earth Observation and Geoinformation, doi:10.1016/j.jag.2005.06.001. 